\title{
Simulation and experiment of rice cleaning in air-separation device based on DEM-CFD coupling method
}

\author{
Xuedong Ma*, Lei Zhao, Bingjiang Guo, He Dang \\ (School of Mechanical Engineering and Automation Institution, University of Science and Technology Liaoning, \\ Anshan 114051, Liaoning, China)
}

\begin{abstract}
In order to study the movement characteristics and separation mechanism of rice and its impurities under the action of airflow, and lower the impurity rate in the cleaning operation process, rice and its impurities were modeled based on the "overlapping multi-sphere clump method", the DEM-CFD coupling method was used to simulate rice cleaning process under different airflow velocity and airflow inclined angle, and combined with aerodynamics, the motion state and separation behavior of rice and its impurities in the flow field. The results showed that under horizontal airflow conditions, the average impurity rate of rice was the lowest when the airflow velocity was $9 \mathrm{~m} / \mathrm{s}$. When the flow velocity remains unchanged and the airflow inclined angle was set at $10^{\circ}$, the average impurity rate decreased, while the entrainment loss rate increased. The airflow velocity was negatively correlated with the impurity rate and positively correlated with the entrainment loss rate, while the airflow inclined angle was negatively correlated with the impurity rate and positively correlated with the entrainment loss rate. By designing and setting up an experimental device, an experiment was carried out with airflow velocity and airflow inclined angle as the factors, and the experimental results were consistent with the simulation results, indicating that it was reliable to study the physical behavior of rice-straw separation in the airflow field by using the DEM-CFD coupling method.
\end{abstract}

Keywords: DEM-CFD, rice cleaning, airflow velocity, airflow inclined angle, experiment

DOI: $10.25165 /$ j.ijabe.20201305.5225

Citation: Ma X D, Zhao L, Guo B J, Dang H. Simulation and experiment of rice cleaning in air-separation device based on DEM-CFD coupling method. Int J Agric \& Biol Eng, 2020; 13(5): 226-233.

\section{Introduction}

As an important process in agricultural production to improve harvest quality and reduce rice doping rate, rice cleaning is an operation of separating fine debris such as rice straw, broken rice straw, chaff and dust from the rice by using the difference in physical properties between rice, rice straw and others components ${ }^{[1-3]}$. The cleaning device used in agricultural production is generally divided into two types, i.e., air-screen separating device and air-separating device, wherein the air-screen separating device separates the materials by utilizing the joint action of airflow and vibrating screen, while the air-separating device relies on the airflow to separate materials with different physical properties. In 1313, the Book of agriculture compiled by Wang Zhen in China's Yuan Dynasty has had a detailed introduction to the structure and use of the air-separation device. Although the agricultural air-separating device has been applied for centuries, the study on the movement of particles and the separation behavior of different particles in the airflow field has been stagnant due to the limit of methods and means.

Discrete Element Method (DEM) is a new discrete media

\section{Received date: 2019-06-24 Accepted date: 2020-06-03}

Biographies: Lei Zhao, Master candidate, research interest: agricultural mechanization engineering, Email: zhaolei9401@163.com; Bingjiang Guo, Master candidate, research interest: agricultural mechanization engineering, Email:guobingjiang0612@163.com; He Dang, Master candidate, research interest: agricultural mechanization engineering, Email: danghe.123@163.com.

*Corresponding author: Xuedong Ma, PhD, Professor, research interest: design of agricultural mechanization equipment. School of Mechanical Engineering and Automation Institution, University of Science and Technology Liaoning, Anshan 114051, Liaoning, China. Tel: +86-412-5929778, Email: madong912@126.com. numerical method to solve and analyze the motion rules and mechanical characteristics of complex Discrete systems ${ }^{[4]}$. In recent years, the application of the discrete element method in agricultural engineering has become more and more mature, Huang et al. used the discrete element method to numerically simulate the fluted-roller meter for metering diammonium phosphate fertilizer and verified the simulation through bench test ${ }^{[5]}$; Ucgul et al. used the discrete element method to simulate the cohesive behavior of soil and the interaction between tillage tools and soil under different water content and conditions, and verified the reliability of the simulation through experiment ${ }^{[6]}$.

Computational Fluid Dynamics (CFD) is a discipline founded on classical mechanics and numerical methods, which is used for the analysis of systems including the physical phenomena of fluid flow, with computer numerical calculations and image display ${ }^{[7]}$. Because there is a large amount of kinetic energy exchange in the process of rice cleaning, and the coupling effect formed by fluid changes, the collision between particles, and interaction of fluid and particles makes the physical properties of the whole system very complicated, in the simulation study of rice cleaning, if the simulation is conducted only with DEM or CFD, it is impossible to describe the interaction between airflow and rice or the rice can only be deemed as a porous medium model, and the influence of rice model on airflow cannot be accurately calculated ${ }^{[8,9]}$.

DEM-CFD coupling method is a new computational model that can not only characterize the geometric shape and collision motion of particles but also calculate fluid distribution based on the multiphase flow model, which is more comprehensive in the simulation of the fluid-particle system compared with the traditional gas-solid two-phase flow model. Using the DEM-CFD coupling method, Yuan et al. ${ }^{[10]}$ simulated and analyzed the movement behavior and screening characteristics of rice threshing 
mixture during cylinder screening ${ }^{[1]}$. Dai et al. simulated tapered threshing and transmission devices based on DEM-CFD coupling method. Thus the material transference and distribution law of flow field in the threshing and transmission device was obtained, the law of changes in speed and displacement of particles and short stalks overtime was acquired, and the motion trajectories and forms of particles under different fixed modes were also studied ${ }^{[12]}$. The above researches are all based on the DEM-CFD coupling method and take the air-screen separating device and tapered threshing and transmission device as the research object, which indicates that the simulation using DEM-CFD coupling method will be the development direction of the theoretical research of agricultural engineering in the future.

Compared with the progress of research on air-screen separating device, the study on the air-separation device is relatively lagging, with rare researches and reports. Therefore, this study uses the DEM-CFD coupling method to simulate the particle cleaning process of rice, rice straw and broken rice straw with the air-separating device as the research object. Combined with aerodynamics it also analyzes the motion state and separation behavior of the three particles in the flow field and studies the relationship among the airflow velocity, the airflow inclined angle and the rice impurity rate and entrainment loss. Moreover, an experimental device was designed in this study, so as to verify the reliability of the simulation of the DEM-CFD coupling method.

\section{Model description}

\subsection{Mathematical model}

When using CFD-DEM coupling method for simulation, the main coupling model includes the Lagrangian model and Eulerian mode $^{[13,14]}$, in which the Lagrangian model uses the uniflow framework, without considering the particle phase volume fraction, while the Eulerian model uses a multiphase flow framework solves, the volume fraction equation, considering the influence of the particle on the flow field. Combined with the obvious blocking effect of rice particles on airflow when the airflow passes through the rice layer, the Eulerian coupling model is used to conduct numerical simulation for the process of cleaning impurity.

In the Eulerian model, the fluid volume fraction term and the motion differential equation are respectively as Equations (1) and $(2)^{[15,16]}$

$$
\begin{gathered}
\frac{\partial\left(\varepsilon_{f} \rho_{f}\right)}{\partial t}+\nabla \cdot\left(\varepsilon_{f} \rho_{f} V_{f}\right)=0 \\
\frac{\partial\left(\varepsilon_{f} \rho_{f} V_{f}\right)}{\partial t}+\nabla \cdot\left(\varepsilon_{f} \rho_{f} v_{f}{ }^{2}\right)=-\nabla P+\nabla \cdot\left(\mu_{f} \varepsilon_{f} \nabla v_{f}\right)+\varepsilon_{f} \rho_{f} g-S
\end{gathered}
$$

where, $\rho_{f}$ is the fluid density, $\mathrm{kg} / \mathrm{m}^{3} ; t$ is time, $\mathrm{s} ; v_{f}$ is the fluid flow rate, $\mathrm{m} / \mathrm{s} ; \varepsilon_{f}$ is the volume fraction of the fluid; $P$ is the pressure on the gas element, $\mathrm{Pa} ; g$ is the acceleration of gravity, $\mathrm{m} / \mathrm{s}^{2} ; \mu_{f}$ is viscosity coefficient; $\nabla$ is the Hamiltonian differential operator; $S$ is the momentum source term.

The momentum source term $S$ is the sum of the airflow resistance acting in the grid cell, and its expression is as Equation $(3)^{[17]}$ :

$$
S=\frac{\sum_{i=1}^{n} F_{i}}{V}
$$

where, $F_{i}$ is the resistance of the particle $i$ to the airflow, N; $V$ is the volume of the grid element, $\mathrm{m}^{3}$.

\subsection{Particle contact impact model}

Computational particle mechanics models can describe interactions between particles and contact mechanics. Considering the contact between particles and the particle velocity is changed based on the contact force, the softball dry contact model and the Hertz-Mindlin (no-slip) contact theory are used here in $^{[18]}$. According to Newton's second law, the equation of motion of the $i$-th particle is ${ }^{[19,20]}$

$$
\begin{gathered}
m_{i}=\frac{d V_{i}}{d t}=m_{i} g+P+\sum_{j=1}^{n_{i}}\left(F_{n, i j}+F_{t, i j}\right) \\
I_{i}=\frac{d \omega_{i}}{d t}=\sum_{j=1}^{n_{i}}\left(T_{t, i j}+T_{r, i j}\right)
\end{gathered}
$$

where, $V_{i}$ is the velocity of particle $i, \mathrm{~m} / \mathrm{s} ; \omega_{i}$ is the angular velocity of particle $i, \mathrm{rad} / \mathrm{s} ; I_{i}$ is the moment of inertia of particle $i, \mathrm{~kg} \cdot \mathrm{m}^{2} ; m_{i}$ is the mass of particle $i, \mathrm{~kg} ; g$ is the acceleration of gravity, $\mathrm{m} / \mathrm{s}^{2} ; P$ is the force received when the particle moves relative to the airflow, $\mathrm{N} ; F_{n, i j}$ is the normal component, $\mathrm{N} ; F_{t, i j}$ is the tangential component, $\mathrm{N} ; T_{t, i j}$ is the tangential moment, $\mathrm{N} / \mathrm{m} ; T_{r, i j}$ is the rolling friction torque, $\mathrm{N} / \mathrm{m}$.

According to the Hertz contact theory, the mathematical description of tangential and normal components is as Equations (6) and $(7)^{[21,22] \text { : }}$

$$
\begin{gathered}
F_{n, i j}=-\frac{4}{3} E^{*} \sqrt{R^{*}}\left(\delta_{n}\right)^{3 / 2} n_{c}-\sqrt{\frac{5}{6} k_{n} m^{*}} \frac{2 \ln \varepsilon}{\sqrt{\ln ^{2} \varepsilon+\pi^{2}}}\left(v_{n, i j} \cdot n_{c}\right) n_{c} \\
F_{t, i j}=-8 G^{*} \sqrt{R^{*} \delta_{n}} \delta_{t}-\sqrt{\frac{5}{6} k_{t} m^{*}} \frac{2 \ln \varepsilon}{\sqrt{\ln ^{2} \varepsilon+\pi^{2}}}\left(v_{t, i j} \cdot n_{c}\right) n_{c}
\end{gathered}
$$

where, $E^{*}$ is the equivalent elastic modulus, $\mathrm{Pa} ; R^{*}$ is the equivalent radius, $\mathrm{m} ; m^{*}$ is the equivalent mass, $\mathrm{kg} ; G^{*}$ is the equivalent shear modulus, $\mathrm{Pa} ; \delta_{n}$ is the normal overlap; $\delta_{t}$ is the tangential overlap; $k_{n}$ is the normal stiffness; $k_{t}$ is the tangential stiffness; $n_{c}$ is the unit vector connecting the centers of two particles; $\varepsilon$ is the elastic recovery coefficient; $v_{n, i j}$ is the relative normal velocity of particle $j$, $\mathrm{m} / \mathrm{s} ; v_{t, i j}$ is the relative tangential velocity of particle $i$ to particle $j$, $\mathrm{m} / \mathrm{s}$.

The mathematical description of the tangential moment and rolling friction moment is as Equations (8) and (9) ${ }^{[23]}$ :

$$
\begin{gathered}
T_{t, i j}=R_{i} F_{n, i j} \\
T_{r, i j}=-\mu F_{t, i j} R_{i} \hat{\omega}_{i}
\end{gathered}
$$

where, $\mu$ is the coefficient of rolling friction; $R_{i}$ is the unit direction vector of particle $i$ centroid to contact point; $\hat{\omega}_{i}$ is the angular velocity unit vector of the particle $i$ contact point.

The force $P$ that the particles are subjected to when moving relative to the airflow is as Equation (10)

$$
P=k \rho A v^{2}=k \rho A\left(v_{q}-v_{x}\right)^{2}
$$

where, $k$ is the drag coefficient, which is related to the shape of the object, the surface characteristics and the Reynolds number; $\rho$ is the air density, $\mathrm{kg} / \mathrm{m}^{3} ; A$ is the Area of material affected by airflow, $\mathrm{m}^{2}$; $v$ is the relative velocity of material and airflow, $\mathrm{m} / \mathrm{s} ; v_{q}$ is the airflow velocity, $\mathrm{m} / \mathrm{s} ; v_{x}$ is the material velocity, $\mathrm{m} / \mathrm{s}$.

\subsection{Geometric model}

In actual operation, the threshing device can remove the rice from the rice panicle and separate the impurities in the rice to a certain extent, but the rice after threshing still contains impurities such as rice straw and broken rice straw. In order to improve rice purity, the rice must be cleaning in the air-separation device after the threshing work is completed. SolidWorks software is used to create a model of air-separating devices. The size of the air separating device model is shown in Figure 1. The device adopts a single air inlet structure. Import the model into ANSYS Workbench to divide the grid. 


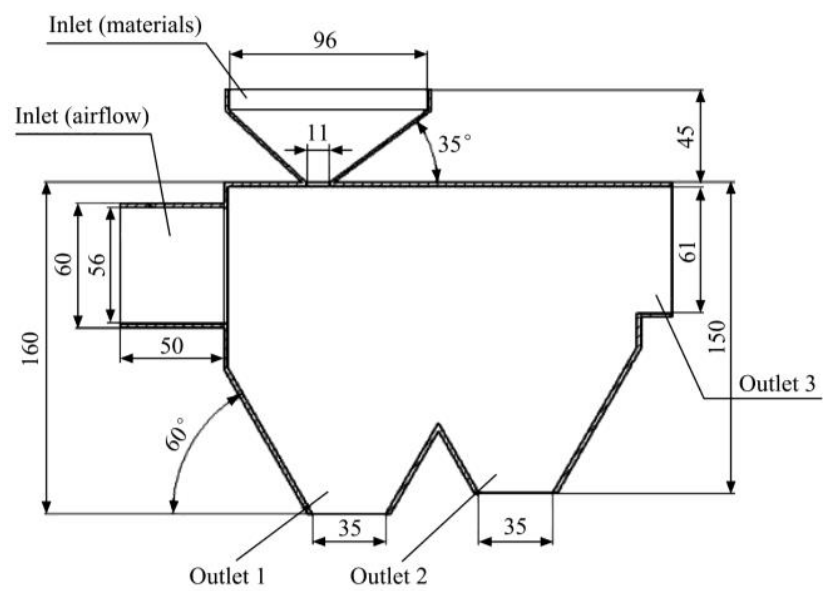

Figure 1 Air-separating device (mm)

In this study, EDEM and Fluent software are used for coupling simulation. Rice, rice straw and broken rice straw are selected as research objects, and rice straw and broken rice straw are defined as impurities in rice. Since only a spherical shape can be chosen for the shape of the particles in the EDEM software, the "overlapping multi-sphere clump method (OMCM)" is used to simplify, overlap and fill the three particles of rice, rice straw and broken straw ${ }^{[24]}$. Figure 2 is a schematic view showing the dimensions of three kinds of particles after filling, wherein the rice is filled by 13 spheres in different particle sizes; the rice straw is filled by 4 spheres with a radius of $2 \mathrm{~mm}$ and 16 spheres with a radius of $1 \mathrm{~mm}$; the broken rice straw is filled by 36 spheres with a radius of $0.5 \mathrm{~mm}$. The model of the three particles in the EDEM software is shown in Figure 3.

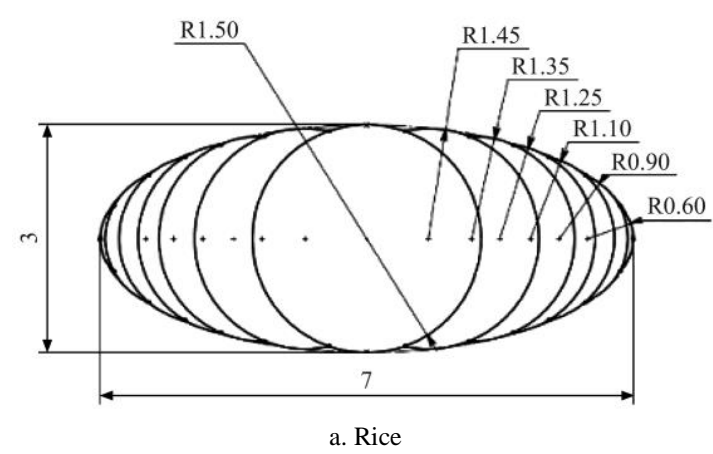

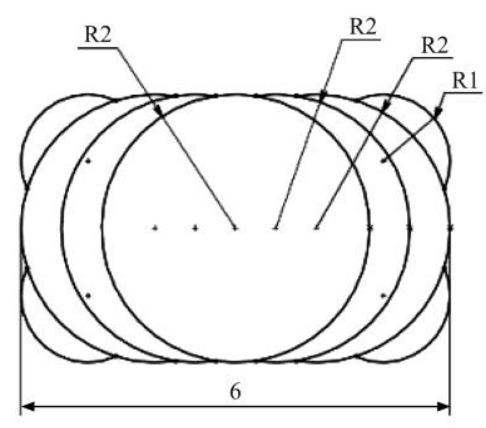

b. Rice straw

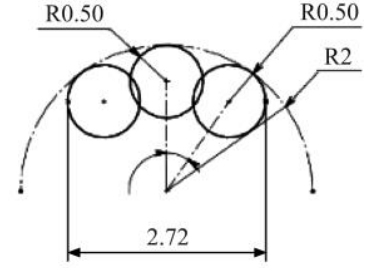

c. Broken rice straw
Figure 2 Schematic diagram of the particle cross section (mm)

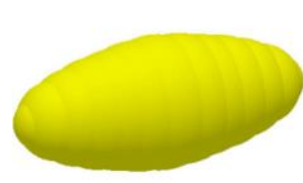

a. Rice

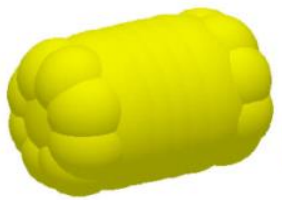

b. Rice straw

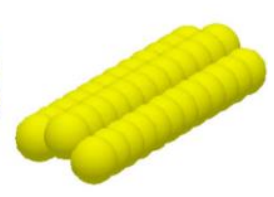

c. Broken rice straw
Figure 3 3D models of particles

\subsection{Setting of simulation parameters}

The mechanical properties and contact coefficients of the material particles in the EDEM software are shown in Tables 1 and $2^{[25-27]}$. The air-separating device is made of steel, and the type of rice is Japonica Rice (South Japonica 9108). Set the number ratio of rice, rice straw and broken rice straw to 4:1:0.25, and the rice production rate to $1200 / \mathrm{s}$, the rice straw production rate to $300 / \mathrm{s}$, and the broken rice straw production rate to $75 / \mathrm{s}$. The simulation time step is set to $33.918 \%$ of the Rayleigh time step, which is $4 \times 10^{-6} \mathrm{~s}$, and the total simulation time is $10 \mathrm{~s}$. The simulation in Fluent 17.0 uses the standard $k-\varepsilon$ turbulence model, and the time step is set to 100 times the time step in EDEM, which is $4 \times 10^{-4} \mathrm{~s}$.

Table 1 Physical parameters of materials

\begin{tabular}{|c|c|c|c|}
\hline \multicolumn{2}{|c|}{ Poisson's ratio } & Shear modulus/Pa & Density $/ \mathrm{kg} \cdot \mathrm{m}^{-3}$ \\
\hline Rice & 0.30 & $2 \times 10^{6}$ & 1380 \\
\hline Stalk & 0.40 & $1 \times 10^{6}$ & 100 \\
\hline Broken rice straw & 0.40 & $1 \times 10^{6}$ & 100 \\
\hline Steel & 0.29 & $7.992 \times 10^{10}$ & 7861 \\
\hline \multicolumn{4}{|c|}{ Table 2 Contact coefficient of materials } \\
\hline & $\begin{array}{l}\text { Coefficient of } \\
\text { restitution }\end{array}$ & $\begin{array}{l}\text { Coefficient of } \\
\text { static friction }\end{array}$ & $\begin{array}{l}\text { Coefficient of } \\
\text { rolling friction }\end{array}$ \\
\hline Rice-rice & 0.2 & 1.0 & 0.01 \\
\hline Rice-stalk & 0.2 & 0.8 & 0.01 \\
\hline Rice-broken rice straw & 0.2 & 0.8 & 0.01 \\
\hline Rice -steel & 0.5 & 0.7 & 0.01 \\
\hline Stalk - stalk & 0.2 & 0.7 & 0.01 \\
\hline $\begin{array}{l}\text { Broken rice straw- broken } \\
\text { rice straw }\end{array}$ & 0.2 & 0.7 & 0.01 \\
\hline Stalk-steel & 0.2 & 0.8 & 0.01 \\
\hline Broken rice straw- steel & 0.2 & 0.8 & 0.01 \\
\hline
\end{tabular}

\section{Simulation and analysis}

\subsection{Airflow velocity analysis}

A particle factory is installed at the inlet of the air-separating device. The rice, rice straw and broken rice straw are produced and freely dropped from the particle factory at the inlet, and the airflow velocity of the air inlet is set to $5 \mathrm{~m} / \mathrm{s}$. Figure 4 is a transient diagram of the material position inside the air-separating device at $2 \mathrm{~s}$. It can be seen from Figure 4 that after the material falls into the airflow action zone, the three material particles exhibit different motion trajectories under the action of the horizontal airflow, and all of the rice falls into outlet 1 , in which some rice straw is doped, and all the materials collected by outlet 2 are rice straw and broken rice straw, so a statistical region of the impurity rate is set at outlet 1 for calculating the impurity rate of the rice collected at outlet 1 , while a statistical region of entrainment loss rate is set at outlet 2 for calculating the entrainment loss rate of rice at outlet 2 .

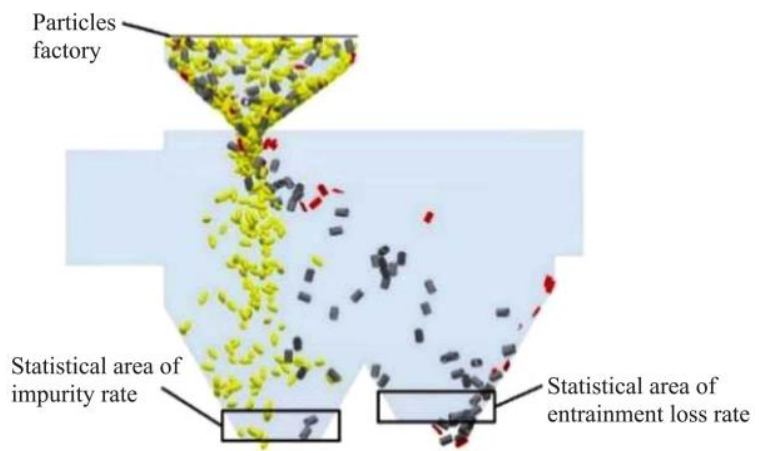

Figure 4 Transient diagram of material particle position $(t=2 \mathrm{~s})$ 
Due to the different aerodynamic characteristics of rice, rice straw and broken rice straw, the vertically falling material will exhibit different trajectories after being subjected to horizontal airflow, and the material will be acted upon by its gravity $G$, air buoyancy $P_{b}$ and horizontal airflow force $P$ in the air-separating device. The resultant force of the three forces is $F$, as shown in Figure 5. The material will move in the direction of $F$, the motion trajectory is parabola, and the moving direction angle of the material is $\alpha$.

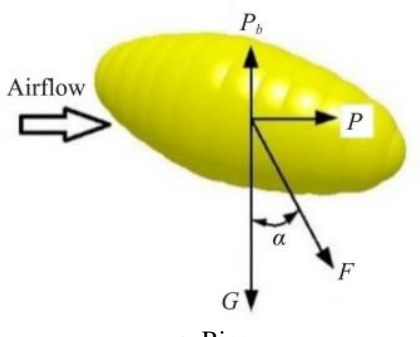

a. Rice

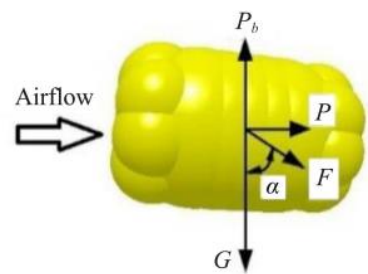

b. Rice straw

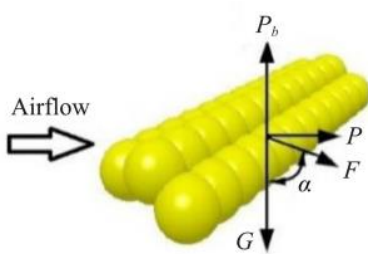

c. Broken rice straw

Figure 5 Force diagram of material particles

If the air buoyancy $P_{b}$ is ignored, then

$$
\tan \alpha=\frac{P}{G}=\frac{k \rho A\left(v_{q}-v_{w}\right)^{2}}{m g}
$$

When the horizontal airflow force $P$ is constant, the smaller the gravity, the larger the moving direction angle $\alpha$ of the material particles. In aerodynamics, $\tan \alpha$ is the flight coefficient of the material in the flow field. As the physical properties such as particle size and density of the material are different, the flight coefficient in the same airflow is also different, when the airflow velocity is constant, the larger the flight coefficient, the greater the horizontal displacement of particles driven by the airflow. It can be known from Equation (11) that, when $\alpha \in(0, \pi / 2)$, the flight coefficient of the material is inversely proportional to its mass, so the rice with a larger mass sinks obviously, and falls first into outlet 1 , while the rice straw and broken straw with relatively lighter quality straws are driven by the horizontal airflow force to make a horizontal projectile motion and fall into outlet 2.

In order to quantitatively describe the impurity rate at outlet 1 , the volume concentration of the rice straw and the broken rice straw is introduced as a measure of the impurity rate, wherein the volume fraction expression of the rice straw and the broken rice straw is as Equation (12):

$$
C_{I}(s, t)=\frac{V_{s}(s, t)+V_{f}(s, t)}{V_{t}(s, t)}
$$

where, $V_{s}(s, t)$ is the volume of rice straw at time $\mathrm{t}$ in region $\mathrm{s}, \mathrm{m}^{3}$; $V_{f}(s, t)$ is the volumes of broken rice straw at time $\mathrm{t}$ in region $\mathrm{s}, \mathrm{m}^{3}$; $V_{t}(s, t)$ is the volume of all materials at time $t$ in region $\mathrm{s}, \mathrm{m}^{3}$.

Figure 6 shows the impurity rate of the rice at outlet 1 after the statistical analysis. It can be seen from the figure that when the horizontal airflow velocity is $5 \mathrm{~m} / \mathrm{s}$, the impurity rate of the rice is unstable and fluctuates greatly. The average impurity content of the obtained rice is $10.575 \%$. During the rice cleaning process by using horizontal airflow, the impurities collected at outlet 2 will be mixed with some rice. Outlet 3 can be neglected since it is an airflow outlet and only a small amount of broken rice straw enter outlet 3, Therefore, the definition of the entrainment loss rate $E_{L}$ is as Equation (13):

$$
E_{L}=\frac{N_{2}}{N_{1}+N_{2}} \times 100
$$

where, $N_{1}$ is the total amount of rice collected at outlet 1 , and $N_{2}$ is the total amount of rice collected at outlet 2 .

The calculation results show that when the airflow velocity is set to $5 \mathrm{~m} / \mathrm{s}$, the entrainment loss rate is $0.066 \%$. Although the entrainment loss rate is relatively satisfying, the impurity rate of the rice at outlet 1 fluctuates significantly, and the average impurity rate of $10.575 \%$ indicates that the cleaning effect is poor when the horizontal airflow velocity is $5 \mathrm{~m} / \mathrm{s}$.

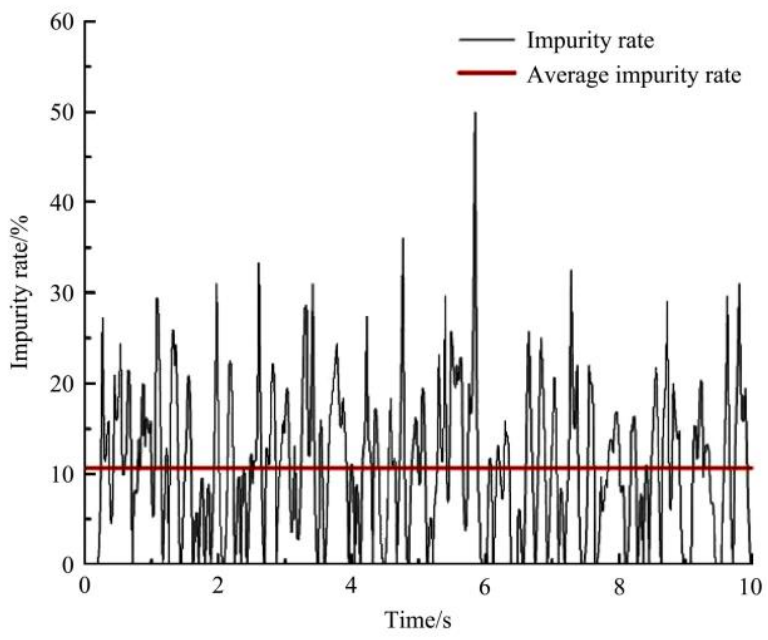

Figure 6 Impurity rate of rice $(v=5 \mathrm{~m} / \mathrm{s})$

Figure 7 shows the impurity rate of rice at outlet 1 when the horizontal airflow velocity is $7 \mathrm{~m} / \mathrm{s}$ and $9 \mathrm{~m} / \mathrm{s}$. It can be known from Figure $7 \mathrm{a}$ that when the horizontal airflow velocity is $7 \mathrm{~m} / \mathrm{s}$, the average impurity rate of rice at outlet 1 is $2.162 \%$, and the entrainment loss rate of rice at outlet 2 is $0.351 \%$. As can be seen from Figure $7 \mathrm{~b}$, when the horizontal airflow velocity is $9 \mathrm{~m} / \mathrm{s}$, the impurity rate of rice fluctuates little, and the whole situation tends to the ideal state. The average impurity rate of rice at outlet 1 is $0.307 \%$, and the entrainment loss rate of rice at outlet 2 is $1.275 \%$.

The data results of the three sets of simulations are shown in Table 3. By comparing the data in Table 3, it is found that when the airflow velocity is adjusted to $7 \mathrm{~m} / \mathrm{s}$, the average impurity rate of the rice at outlet 2 decreases by $8.413 \%$ compared to that when the airflow velocity is $5 \mathrm{~m} / \mathrm{s}$; the entrainment loss rate increases by $0.291 \%$ compared to the airflow velocity is $5 \mathrm{~m} / \mathrm{s}$. When the airflow velocity is adjusted to $9 \mathrm{~m} / \mathrm{s}$, the standard deviation of rice impurity rate in the cleaning process is 0.5 times of $7 \mathrm{~m} / \mathrm{s}$, which indicates that the fluctuation of the impurity rate of the rice is smaller when the airflow velocity is $9 \mathrm{~m} / \mathrm{s}$. The impurity rate is reduced by $1.855 \%$, and the entrainment loss rate is increased by $0.924 \%$.

Table 3 Simulation results

\begin{tabular}{cccc}
\hline $\begin{array}{c}\text { Velocity of } \\
\text { airflow } / \mathrm{m} \cdot \mathrm{s}^{-1}\end{array}$ & $\begin{array}{c}\text { Average impurity } \\
\text { rate/\% }\end{array}$ & $\begin{array}{c}\text { Standard deviation of } \\
\text { impurity rate }\end{array}$ & $\begin{array}{c}\text { Entrainment loss } \\
\text { rate/\% }\end{array}$ \\
\hline 5 & 10.575 & 0.107 & 0.066 \\
7 & 2.162 & 0.053 & 0.351 \\
9 & 0.307 & 0.021 & 1.275 \\
\hline
\end{tabular}




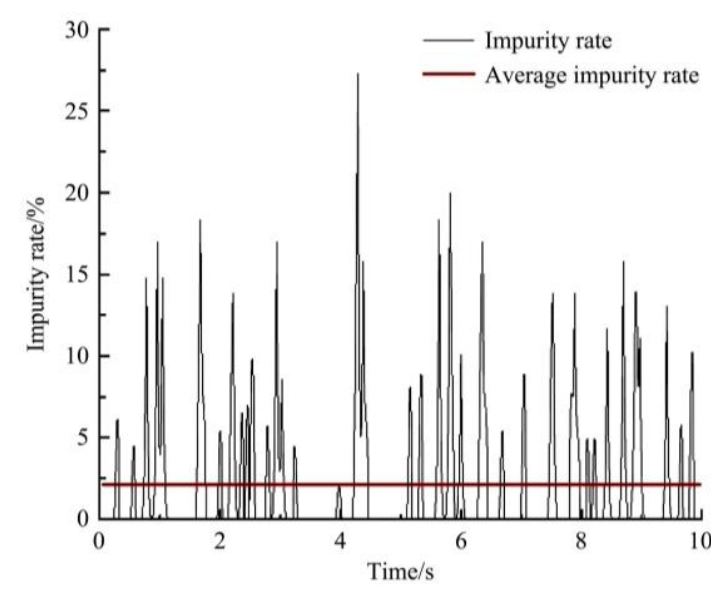

a. $v=7 \mathrm{~m} / \mathrm{s}$

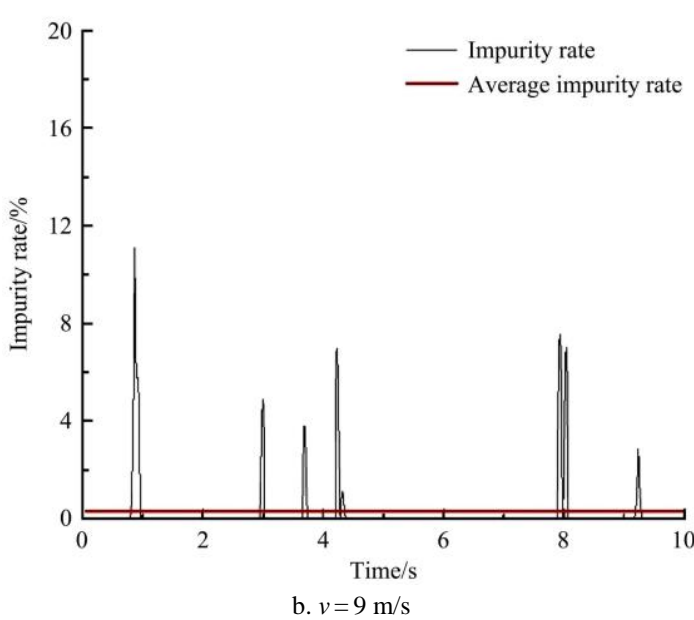

Figure 7 Impurity rate of rice

In the actual production process, in order to reduce the impurity rate and entrainment loss rate of the rice, the impurities containing the loss of rice are often subjected to secondary cleaning. By comprehensively considering the impurity rate and entrainment loss rate under the three airflow velocity, the cleaning effect is better when the airflow velocity is $9 \mathrm{~m} / \mathrm{s}$.

\subsection{Airflow inclined angle analysis}

In order to research the influence of the airflow inclined angle on the material's motion behavior and the quality of the cleaning, the air inlet of the air-separating device is changed from $0^{\circ}$ (horizontal) to $10^{\circ}$, that is, the airflow inclined angle $\beta$ becomes $10^{\circ}$. Figures $8 \mathrm{a}$ and $8 \mathrm{~b}$ show the airflow velocity contours under the condition that the air inlet inclined angle is $0^{\circ}$ and $10^{\circ}$, respectively when the airflow velocity is $9 \mathrm{~m} / \mathrm{s}$. It can be seen from the figure that the airflow under both conditions has a laminar flow phenomenon in the air-separating device. The airflow velocity in the near-wall area is relatively small, and the airflow velocity at the air inlet is greater than the airflow velocity at outlet 3. The airflow velocity has a transition zone inside the device, which is formed because the rice falls from the inlet, the airflow interacts with the rice and is hindered by the rice and then spreads to the surrounding areas, causing a certain loss of airflow velocity. By comparing Figures $8 \mathrm{a}$ and $8 \mathrm{~b}$, it can be seen that changing the airflow inclined angle has little effect on the overall distribution law of the airflow velocity.

Figure 9 shows the impurity rate of the rice at outlet 1 at each time when the airflow velocity is $9 \mathrm{~m} / \mathrm{s}$ and the airflow inclined angle of $10^{\circ}$. It can be seen from the figure that when the airflow inclined angle is set to $10^{\circ}$, the average impurity rate is $0.282 \%$. The entrainment loss rate of the rice obtained after the calculation is $1.583 \%$. By comparing to the average impurity rate and entrainment loss rate of the rice when the airflow inclined angle is $0^{\circ}$ (horizontal) at the same airflow velocity, it shows that the average impurity rate of the rice is reduced by $0.025 \%$ when the inlet is inclined by $10^{\circ}$, and the entrainment loss rate is increased by $0.308 \%$.

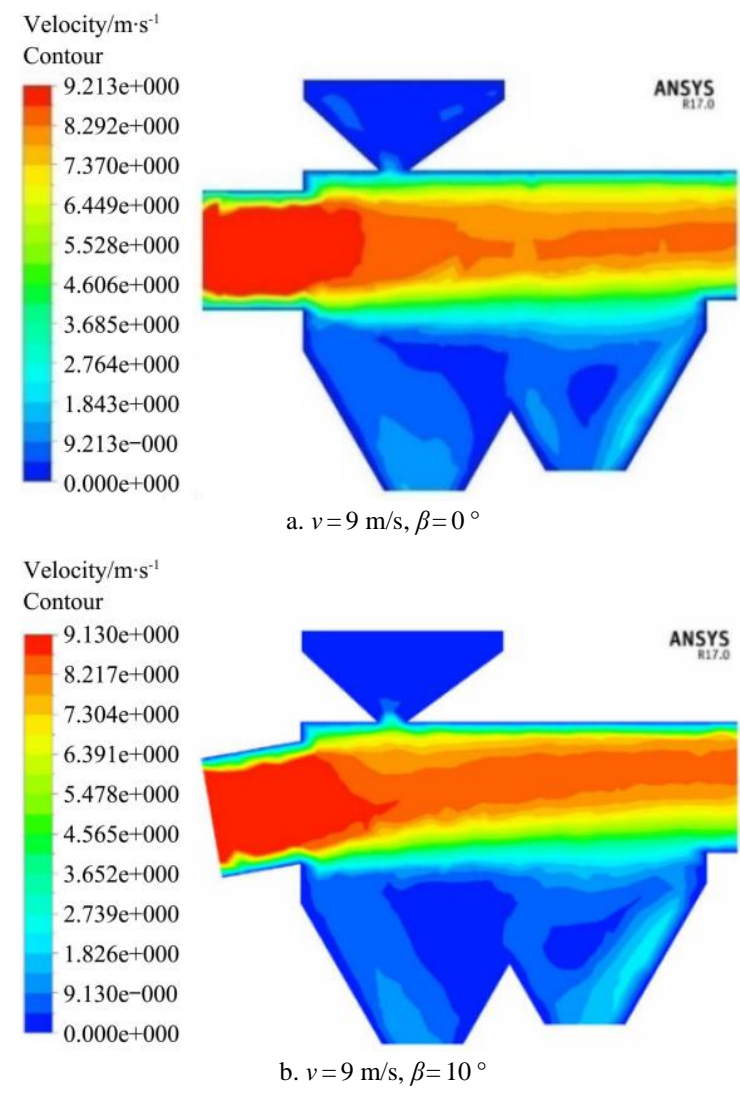

Figure 8 Airflow velocity contour diagram

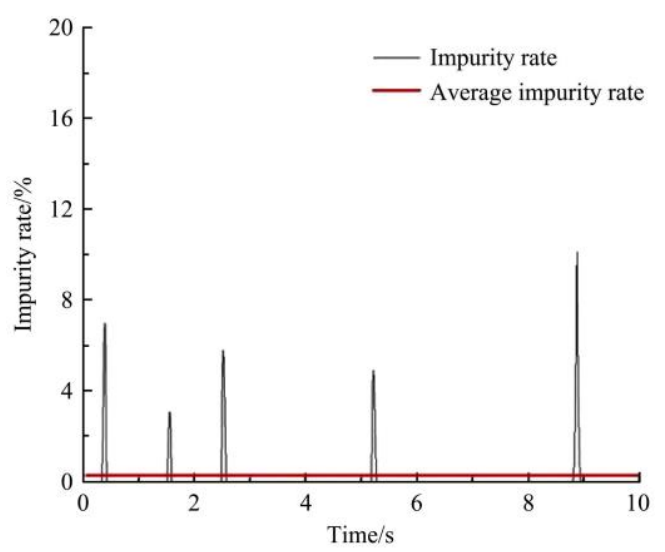

Figure 9 Impurity rate of rice $\left(v=9 \mathrm{~m} / \mathrm{s}, \beta=10^{\circ}\right)$

\subsection{Discussion}

Figure 10 shows the influence of different airflow velocity and airflow inclined angle on the average impurity rate and entrainment loss rate. It can be seen from the figure that, when the airflow inclined angle is constant, the larger the airflow velocity, the lower the average impurity rate and the higher the entrainment loss rate. With the combination of research results in section 3.1, it shows that due to the increase of airflow velocity, the horizontal force $P$ applied to the material increases, the angle $\alpha$ between the material motion trajectory and the gravity also increases, the horizontal displacement of the material gets larger, and more rice straw and broken rice straw fall into outlet 2 , eventually leading a reduction of the average impurity rate of the rice at outlet 1 ; As the horizontal 
displacement of the three particles increases, the quantity of rice falling into outlet 2 increases, so the entrainment loss rate will also increase.

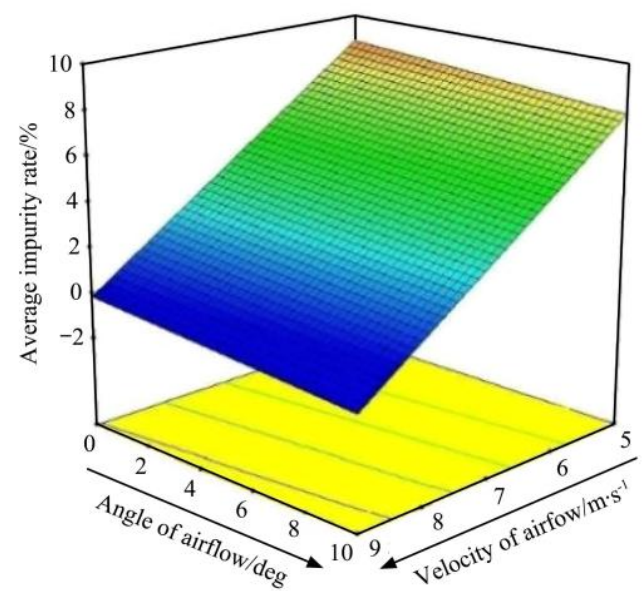

a. Impurity rate

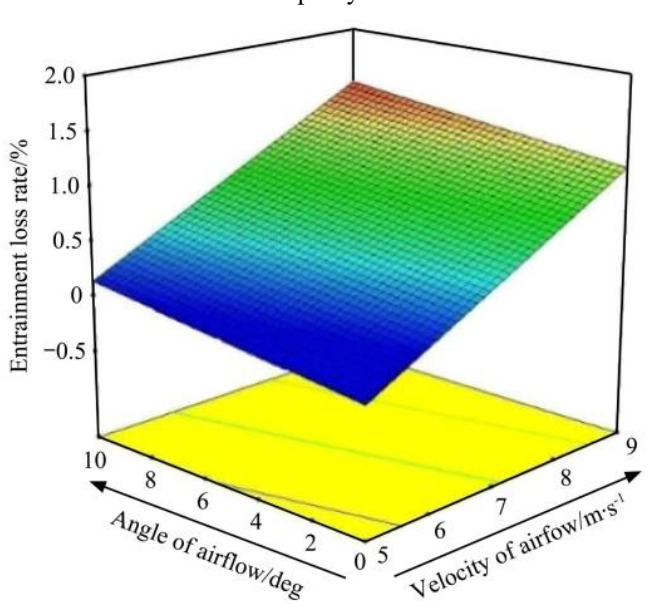

b. Entrainment loss rate

Figure 10 Response surface diagram of airflow velocity and airflow inclined angle to average impurity rate and entrainment loss rate

It can be seen from Figure 10 that, when the airflow velocity is constant, the greater the airflow inclined angle, the lower the average impurity rate, and the higher the entrainment loss rate. The histogram in Figure 11 shows the velocity in the horizontal direction of three particles when the airflow velocity is $9 \mathrm{~m} / \mathrm{s}$, and the airflow inclined angle is from $0^{\circ}$ to $10^{\circ}$. We can see from the histogram that no matter for the rice, rice straw, or broken rice straw, the larger the airflow inclined angle, the greater the velocity. This indicates that the horizontal displacement of the three kinds of

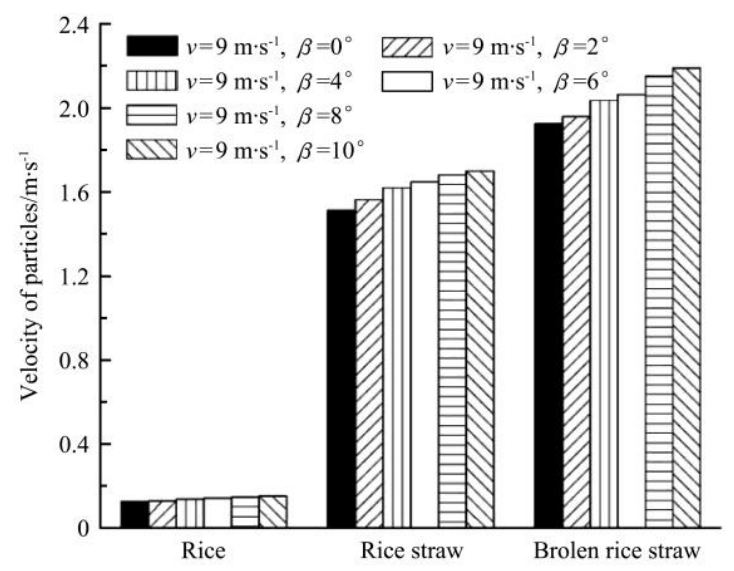

Figure 11 Velocity of the three materials in the horizontal direction

material particles increase with the increase of airflow inclined angle increases, so at the same airflow velocity, the large the airflow inclined angle, the lower the average impurity rate, and the higher the entrainment loss rate.

In summary, the airflow velocity is negatively correlated with the average impurity rate and positively correlated with the entrainment loss rate; the airflow inclined angle is negatively correlated with the average impurity rate and positively correlated with the entrainment loss rate.

\section{Experimental verification}

In order to verify the reliability of using the DEM-CFD coupling method in the rice cleaning simulation study, an experimental device is designed for the experimental verification of the stimulation of the rice cleaning process. Figure 12a is the structure diagram of the experimental device. As shown in the figure, the air-separating chamber is fixed on the base plate by two supports, a baffle plate fixed on the base plate is equipped between outlet 1 and outlet 2, which is used to separate the materials discharged from two outlets. A convert connector is equipped at the entrance of the air-separating chamber, which is used to connect the ventilation pipe and air inlet. One end of the ventilation pipe is fastened at the outlet of the fan by an American hose clamp, the other end is secured to the convert connector by an American hose clamp.

Figure $12 \mathrm{~b}$ is a physical diagram of the experimental device, wherein the model of the air-separating device is formed by $3 \mathrm{D}$ printing, and the material is made of the photosensitive resin with high mechanical strength and versatility. For the convenience of observation, the side panel of the device is made of the transparent acrylic board; the rated voltage of the fan is $220 \mathrm{~V}$, the power is $60 \mathrm{~W}$, the speed of revolution is $2800 \mathrm{r} / \mathrm{min}$; the working voltage of the speed control switch is AC 180-250 V; a PU polyurethane duct is chosen to be the ventilation pipe, and the measurement range of the anemometer is $0-30 \mathrm{~m} / \mathrm{s}$.

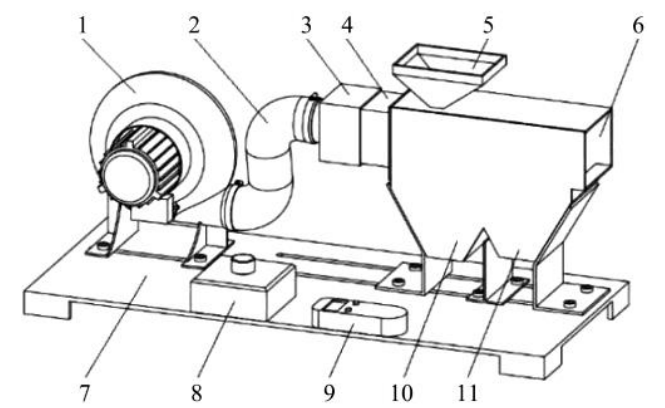

1. Blower 2. Ventilation pipe 3. Ventilation pipe connector 4. Inlet (airflow) 5. Inlet (materials) 6. Outlet 3 7. Base plate 8. Speed control switch 9. Handheld anemometer 10 . Outlet 1 11. Outlet 2

a. Schematic diagram of the experimental device

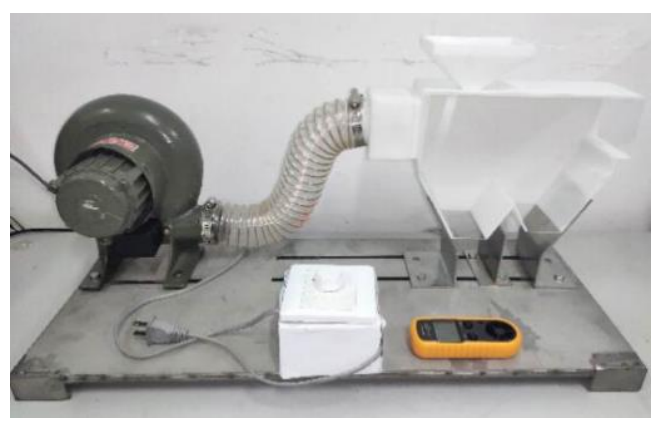

b. Physical diagram of the experimental device

Figure 12 Experimental device of the schematic diagram and the physical diagram 
The airflow velocity is measured by a hand-held anemometer. The airflow velocity is adjusted to the velocity required for the experiment by the speed control switch. The rice mixed with the rice straw and the broken rice straw is poured into the cleaning device from the inlet. Figure 13 shows the simulation transient diagram in the EDEM software and the experiment transient diagram at $4 \mathrm{~s}$ when the airflow velocity is $5 \mathrm{~m} / \mathrm{s}$. Comparing Figures $13 \mathrm{a}$ and $13 \mathrm{~b}$, it can be seen that the velocity vector trajectory of the rice, rice straw and broken rice straw in the simulation is basically similar to that in the experiment.

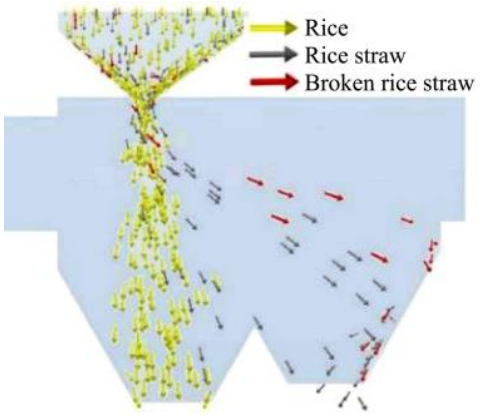

a. EDEM simulation

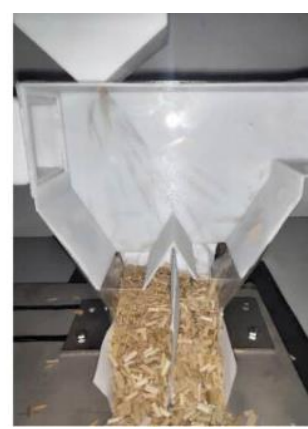

b. Experiment
Figure 13 Simulation of transient diagram and experiment transient diagram $(v=5 \mathrm{~m} / \mathrm{s})$

In order to facilitate the observation of the experimental results, the materials discharged from each outlet are placed on a black test stand. Figure 14 shows the experimental results when the airflow rate is $5 \mathrm{~m} / \mathrm{s}$. As can be seen from the figure, most of the particles discharged from outlet 1 were rice, but the impurity rate is high, and some rice straw is doped. The particles discharged from outlet 2 were all rice stalks and broken rice stalks, and the particles discharged from outlet 3 were all broken rice stalks.

Figure 15 shows the data comparison between the experiment results and the simulation results. It can be seen from the figure that after changing the experiment parameters, the change tendency of the experiment results and the simulation results are basically consistent. However, it is also found that there are some errors in these data. In the experiment, the impurity rate and entrainment loss rate of rice are greater than the data obtained from the simulation. This is due to the randomness of the volume and mass of rice straws in the experiment compared with that in the simulation. Some rice straws with larger mass cannot be separated from rice under the action of airflow, and with the rice entering outlet 1 , it leads to the impurity rate in the experiment is higher than the simulation data. In addition, there are shriveled and insect ate hollow rice in the experiment, which is more easily carried to outlet 2, resulting in a higher entrainment loss rate than the simulation data. In general, the experiment data is close to the simulation data, which verifies the accuracy and feasibility of the simulation research on rice cleaning based on DEM-CFD coupling method.

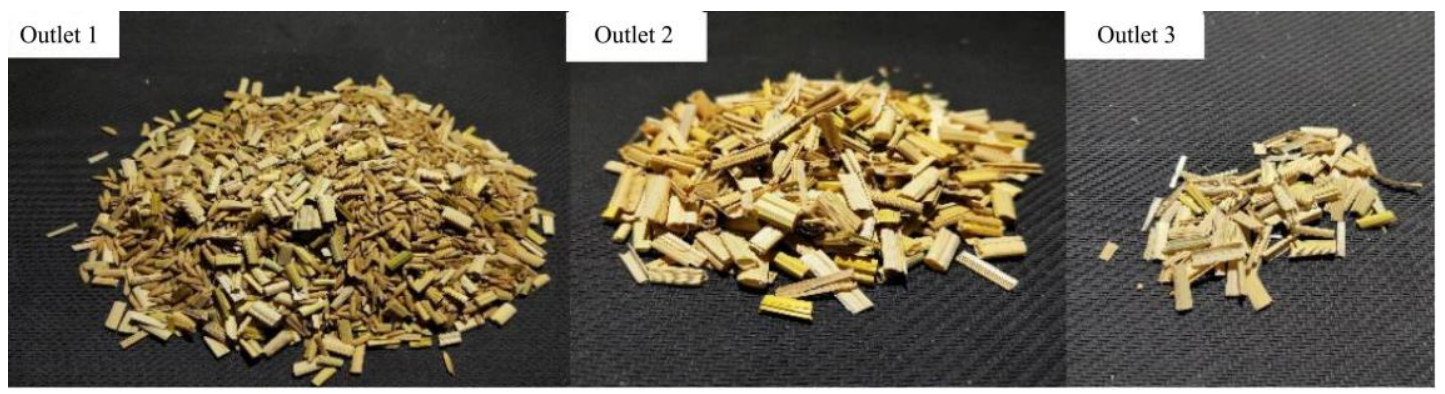

Figure 14 Experiment results $(v=5 \mathrm{~m} / \mathrm{s})$
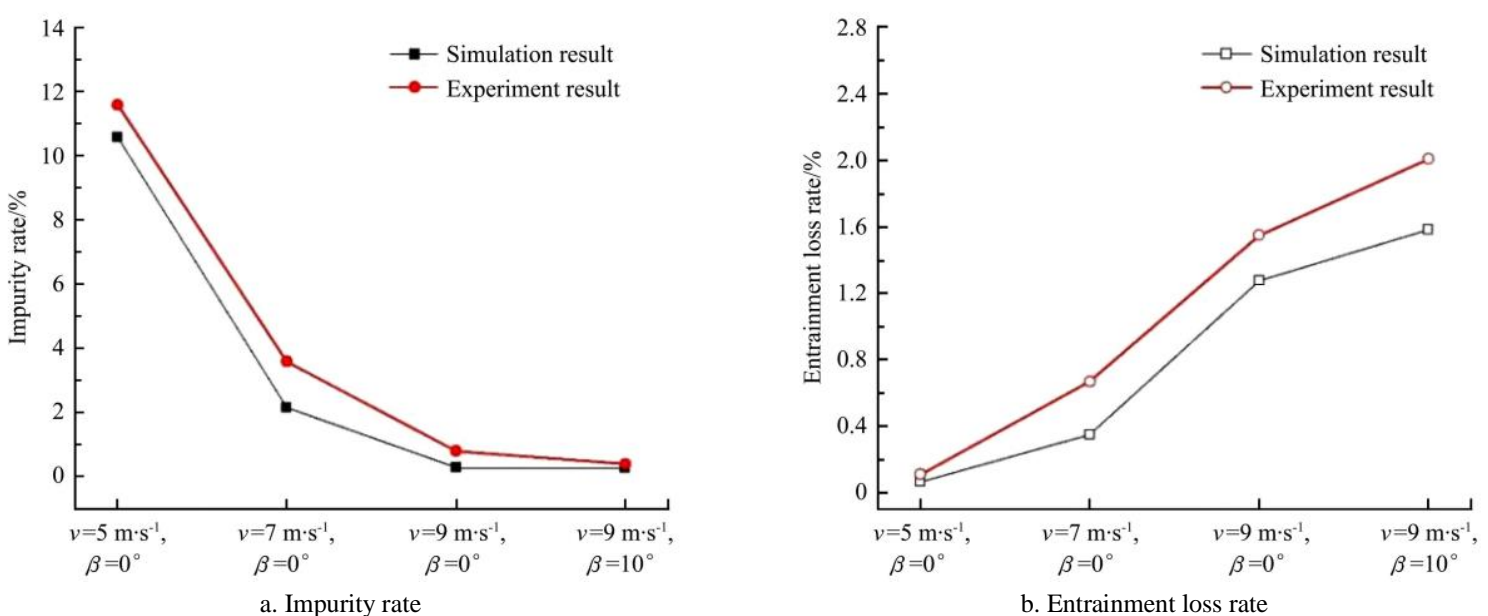

Figure 15 Comparison of experiment results and simulation results

\section{Conclusions}

The DEM-CFD coupling method was used to simulate the process of rice cleaning under different airflow velocity and airflow inclined angle. The aerodynamic analysis of the stress state and the movement tendency of rice, rice straw and broken rice straw in the flow field was analyzed. Through statistical calculation, the rice impurity rate and entrainment loss rate of rice under different parameters were obtained, and the following conclusions were drawn out:

(1) Due to the difference in aerodynamic characteristics of rice, rice straw and broken rice straw, they produce different movement trends in the flow field. The material quality is inversely proportional to its flight coefficient, that is, the smaller the mass, the larger the flight coefficient, and the greater the horizontal displacement of the material. Therefore, the three particles are 
separated in the air-separating device and fall to different outlets.

(2) When the horizontal airflow velocity is set to $5 \mathrm{~m} / \mathrm{s}$, the average impurity rate of the rice is $10.575 \%$, and the entrainment loss rate is $0.066 \%$. When the airflow velocity increases, the horizontal force $\mathrm{P}$ of the material increases, the angle $\alpha$ between the material trajectory and the gravity increases, the displacement in the horizontal direction of the material becomes larger, so the impurity rate of the rice decreases, and the entrainment loss rate increases accordingly.

(3) When the horizontal airflow velocity is set to $9 \mathrm{~m} / \mathrm{s}$ and the airflow inclined angle is $10^{\circ}$, the average impurity rate of the rice is $0.282 \%$, and the entrainment loss rate is $1.583 \%$. At the same airflow velocity, the larger the airflow inclined angle, the lower the average impurity rate, and the higher the entrainment loss rate.

(4) Through comparative analysis, the experiment results are close to the simulation results. The DEM-CFD coupling method can be used for the simulation analysis of the rice cleaning process in an effective way. The parameters obtained can provide a reference basis for the design of the air-separating device.

\section{Acknowledgements}

The authors acknowledge that this work was financially supported by the National Natural Science Foundation of China (Grant No. 51775258).

\section{[References]}

[1] Binelo M O, de Lima R F. Modelling of the drag force of agricultural seeds applied to the discrete element method. Biosystems Engineering, 2019; 178: 168-175.

[2] Du X Q, Xiao M H, Hu X Q, Chen J N, Zhao Y. Numerical simulation and experiment of gas-solid two-phase flow in cross-flow rice cleaning device. Transactions of the CSAE, 2014; 30(3): 27-34. (in Chinese)

[3] Fu J, Chen Z, Han L J, Ren L Q. Review of rice threshing theory and technology. Int J Agric \& Biol Eng, 2018, 11(3): 12-20.

[4] Katterfeld A, Wensrich C. Understanding granular media: From fundamentals and simulations to industrial application. Granular Matter, 2018, 19(4): 83. doi: 10.1007/s10035-017-0765-y.

[5] Huang Y X, Wang B T, Yao Y X, Ding S P, Zhang J C, Zhu R X. Parameter optimization of fluted-roller meter using discrete element method. Int J Agric \& Biol Eng, 2018; 11(6): 65-72.

[6] Ucgul M, Fielke J M, Saunders C. Three-dimensional discrete element modelling (DEM) of tillage: Accounting for soil cohesion and adhesion. Biosystems Engineering, 2014; 129: 298-306.

[7] Hu J, Fan G. CFD simulation of heating process of greenhouse irrigation water in wintering period. Applied Engineering in Agriculture, 2017; 33(4): 575-586.

[8] Han D D, Zhang D X, Jing H R, Yang L, Cui T, Ding Y Q, et al. DEM-CFD coupling simulation and optimization of an inside-filling air-blowing maize precision seed-metering device. Computers and Electronics in Agriculture, 2018; 150: 426-438.

[9] He Y, Bayly A E, Hassanpour A. Coupling CFD-DEM with dynamic meshing: A new approach for fluid-structure interaction in particle-fluid flows. Powder Technology, 2018; 325: 620-631.

[10] Ren B, Zhong W Q, Chen Y, Chen X, Jin B S, Yuan Z L, et al CFD-DEM simulation of spouting of corn-shaped particles. Particulogy, 2012; 10(5): 562-572.

[11] Yuan J B, Wu C Y, Li H, Qi X D, Xiao X X, Shi X X. Movement rules and screening characteristics of rice-threshed mixture separation through a cylinder sieve. Computers and Electronics in Agriculture, 2018; 154: 320-329.

[12] Dai F, Song X F, Zhao W Y, Han Z S, Zhang F W, Zhang, S L. Motion simulation and test on threshed grains in tapered threshing and transmission device for plot wheat breeding based on CFD-DEM. Int $\mathbf{J}$ Agric \& Biol Eng, 2019; 12(1): 65-72.

[13] Mahmudah R S N, Kumabe M, Suzuki T, Guo L, Morita K. 3D Simulation of solid-melt mixture flow with melt solidification using a finite volume particle method. Journal of Nuclear Science and Technology, 2011; 48(10): 1300-1312.

[14] Sturm M, Wirtz S, Scherer V, Denecke J. Coupled DEM-CFD simulation of pneumatically conveyed granular media. Chemical Engineering \& Technology, 2010; 33(7): 1184-1192.

[15] Lei X L, Liao Y T, Liao Q X. Simulation of seed motion in seed feeding device with DEM-CFD coupling approach for rapeseed and wheat. Computers and Electronics in Agriculture, 2016; 131: 29-39.

[16] Zhou L, Zhang L J, Bai L, Shi W D, Li W, Wang C, Agarwal R. Experimental study and transient CFD/DEM simulation in a fluidized bed based on different drag models. RSC Advances, 2017; 7(21): 12764-12774.

[17] Adema A T, Yang $\mathrm{Y} X$, Boom R. Discrete Element Method-Computational fluid dynamic simulation of the materials flow in an Iron-making blast furnace. ISIJ International, 2010; 50(7): 954-961.

[18] Wiacek J. Geometrical parameters of binary granular mixtures with size ratio and volume fraction: experiments and DEM simulations. Granular Matter, 2016; 18(3): 42. doi: 10.1007/s 10035-016-0642-0

[19] Li H, Wang J S, Yuan J B, Yin W Q, Wang Z M, Qian Y Z. Analysis of threshed rice mixture separation through vibration screen using discrete element method. Int J Agric \& Biol Eng, 2017; 16(6): 231-239.

[20] Ma X D, Zhang Y B, Liu Y, Zheng X W. Simulation of grain segregation under horizontal rotational oscillations. Granular Matter, 2016; 18(1): 8. doi: 10.1007/s10035-015-0598-5.

[21] Alberto D R, Francesco P D M. Comparison of contact-force models for the simulation of collisions in DEM-based granular flow codes. Chemical Engineering Science, 2004; 59(3): 525-541.

[22] Langston P A, Tuzun U, Heyes D M. Discrete element simulation of granular flow in 2D and 3D hoppers: Dependence of discharge rate and wall stress on particle interactions. Chemical Engineering Science, 1996; 50(6): 967-987.

[23] Zhou Y C, Wright R Y, Yang B H, Xu A B. Rolling friction in the dynamic simulation of sandpile formation. Physica A, 1999; 269(2): 536-553.

[24] Zhou Y, Wang H B, Zhou B, Li J. DEM-aided direct shear testing of granular sands incorporating realistic particle shape. Granular Matter, 2018; 20(3): 55. doi: 10.1007/s10035-018-0828-8.

[25] Markauskas D, Kacianauskas R. Investigation of rice flow by multi-sphere particle model with rolling resistance. Granular Matter, $2011 ; 13(2), 143-148$.

[26] Liang Z W, Li Y M, Xu LZ, Zhao Z. Sensor for monitoring rice sieve losses in combine harvesters. Biosystems Engineering, 2016; 147: 51-66.

[27] Ma Z, Li Y M, Xu L Z. Discrete-element method simulation of agricultural particles' motion in variable-amplitude screen box. Computers and Electronics in Agriculture, 2015; 118: 92-99. 